\title{
L'addition de tourteau de coton dans les blocs mélasse-urée
}

\author{
$\mathrm{RH}$ Bosma 1, S Bagayogo 2 \\ 'Roghorst 363, Wageningen, Pays Bas; '2ESPGRN, BP186, Sikasso, Mali
}

Les pâturages dans la zone humide du Mali sud sont abondants et localement riches en plantes pérennes qui repoussent après les feux précoces. Néanmoins, en saison sèche après la vaine pâture, la faible qualité du fourrage (Leloup et Traoré, 1989, La situation fourragère dans le sud-est du Mali, DRSPR/KIT, I) et la chaleur limitent l'ingestion des ruminants. Les bovins et les ovins peuvent y perdre 10 à $20 \%$ de leur poids vif. Les agroéleveurs ressentent le besoin de complémenter les boeufs de traction et les vaches suitées. L'accès à l'aliment bétail, un sous-produit de l'industrie cotonnière, reste limité et le coût d'opportunité de la plupart des cultures fourragères est élevé. Les blocs mélasse-urée, introduits au Mali pour valoriser le fourrage des parcours (Sansoucy, 1986, Rev Mond Zoot, 57) ont été utilisés en complément de l'aliment bétail (contenant $76 \%$ de coques et $20 \%$ d'expeller de coton) avec une amélioration de $66 \%$ de gain de poids $(p<$ 0,05 ) et, surtout, avec un taux de rémunération de l'investissement supplémentaire intéressant.

Ce résultat a conduit à ajouter du tourteau de coton, disponible localement, aux blocs mélasse-urée comme suggéré par Leng (1986, Drought Feeding Strategies, theory and practice). Cette adjonction réduit le besoin en ciment. Le bloc "métocour" composé de: $21 \%$
MElasse, $39 \%$ TOurteaux de COton, $8 \%$ Urée, $22 \%$ son de Riz, $3 \%$ sel, $1 \%$ phosphate naturel et $5 \%$ ciment, a été testé sur des boeufs de traction au pâturage dans quatre zones. Le lot témoin consommait des pailles de sorgho enrichies de mélasse-urée + tourteau de coton (Bosma et Bengaly, 1996, Ann Zootech, 45, suppl, ) en saison chaude. Bien que les paysans aient apprécié l'effet favorable sur les boeufs de labour en saison post-humide, le gain supplémentaire est annulé par la croissance compensatrice du témoin lors de la vaine pâture. Pendant la saison sèche chaude, l'ingestion de $250 \mathrm{~g}^{\mathrm{j}} \mathrm{j}^{-1}$ de bloc "métocour" permet aux bovins en zone humide de maintenir leur poids. La distribution des pailles enrichies est aussi efficace et aussi coûteuse, mais plus exigeante en main d'oeuvre. Dans les zones moins arrosées, la distribution du bloc «métocour» n'empêche pas des pertes de poids sur des végétations sèches peu denses en saison sèche chaude. En zone humide, l'efficacité du bloc "métocour» a étonné les paysans: "même les animaux qui léchaient seulement le bloc au retour dans le parc étaient en bonne condition pour le travail". Les blocs sont fabriqués par les paysans des villages faisant partie du réseau de recherche et de vulgarisation. Le facteur limitant le développement des blocs est la difficulté de se procurer le tourteau de coton.

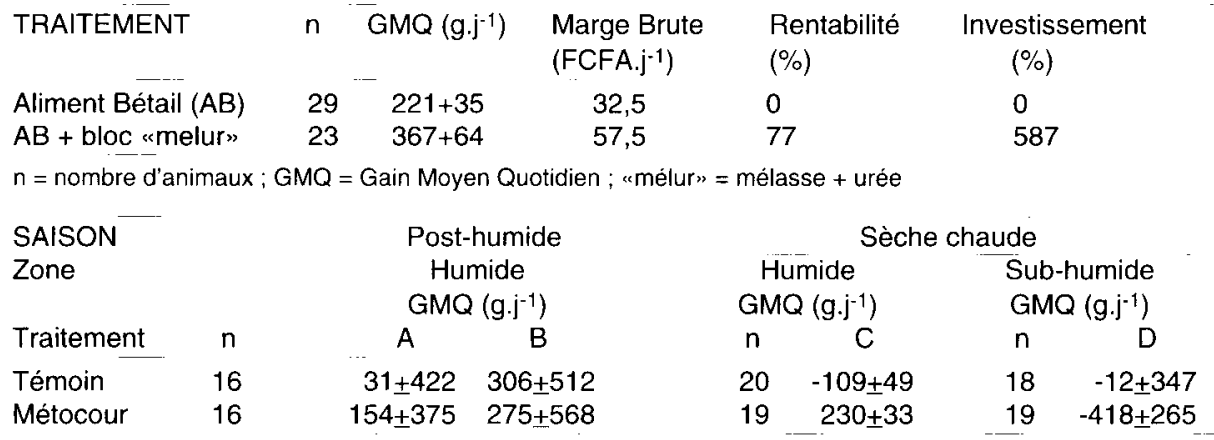

$A=8 / 10$ à $8 / 11,1992 ; B=8 / 11$ à $20 / 12,1992 ; C=5 / 04$ à $8 / 05,1991 ; D=10 / 04$ à 16/05, 1991

En période $B$, pendant la vaine pâture, le métocour n'était plus distribué. 